\title{
A Review on Leaves Diseases Segmentation and Classification Techniques
}

\author{
Soumya Ranjan Sahu*, Chandra Sekhar Panda
}

Department of Computer Science and Application, Sambalpur University, Jyoti Vihar, Burla, Odisha, India

\begin{abstract}
Agriculture plays a major role in our society. Most of the people depend on agriculture for their living. It becomes very important part of society for their livelihood. But there are some problems on agriculture that directly or indirectly affect human health and also economy. The major problem for agriculture is the plant diseases. This paper is based on a survey of different types of techniques used for segmenting and classification of plant diseases by using image processing techniques. By these techniques, we can easily detect the area of the infected part or can identify the type of disease. This paper gives various techniques used by various authors to detect the disease quickly and accurately. They used different types of segmentation techniques like region based, clustering, thresholding etc. to detect the infected part of the leaves and by using the classifier they classify the disease name. The traditional method of naked eye observation can be overcome by introducing these methods. Main focus of our work is to analysis of fast and accurate techniques to identify the plant diseases.
\end{abstract}

Keywords: Plant diseases, Image pre-processing, Segmentation, Clustering, Thresholding, Region based, Watershed, SVM

\section{INTRODUCTION}

India is a cultivated country where most of the people are strictly depend upon agriculture. Undoubtedly we can say agriculture is the backbone of India. The farmers have large range of selection in suitable crops, vegetables and fruits. The plant plays the major role of energy and the main source for livelihood. But the agricultural crops can be affected by some disease causing organisms like bacteria, fungi, pathogens. Except this, the unhealthy weather and the environment also responsible for diseases. In most cases diseases are seen on the leaves, fruits and the stem, of the plant.
These diseases can be easily detected and recognised by naked eye observation. But this is very old and classical method to detect the plant diseases. This method of observation is very slow and also gives less accuracy.

To overcome these problems there are many techniques used to detect different types of plant diseases. Using digital image processing the detection of plant disease is so easy and also less time consuming. It also gives the best accuracy as compared to the naked eye observation. For accurate detection of plant disease different author gives different techniques. They developed a lot of algorithm for this purpose. Some algorithm gives the best accuracy and some gives the low accuracy. 


\section{PLANT DISEASES}

Some biological agents that directly or indirectly affect the plant, known as plant diseases. The biological agents are known as pathogens. Some common pathogens are-

1. Virus

2. Bacteria

3. Fungi

4. Nematodes

Besides these pathogens there are also some nonpathogenic disease may occur when the $\mathrm{pH}$ value, moisture climate change with respect to the environment

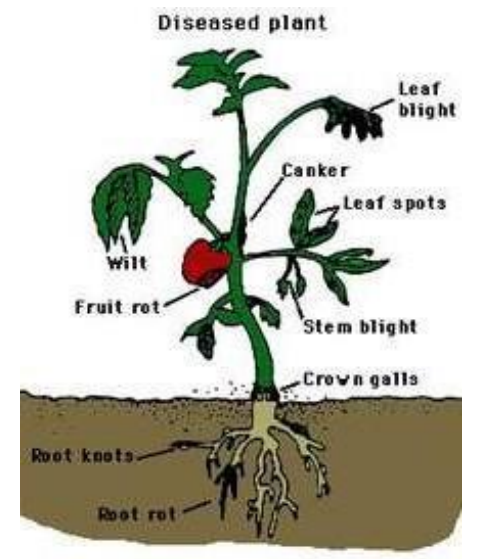

Fig. 1 Possible disease symptoms on plant

\section{METHODS USED TO SEGMENTING THE IMAGE}

There are various methods used in image processing for segmentation. There are various methods used to detect the area plant disease by segmenting. Some of them are-

\section{Clustering}

2. Thresholding

3. Edge based segmentation

4. Region based segmentation

5. Watershed

\subsection{Clustering}

Clustering technique used for segmenting the image into various cluster. Image is first converted into histogram and then clustering is applied on it. There are different types of clustering methods like, K-means clustering, Fuzzy C-means clustering, mountain clustering method and subtractive clustering method. One of the basic clustering algorithms is K-means, which is intended for segmentation in textured images [20]. It clusters same pixels to segment the image.

Xiaojing Niu [24] proposed an unsupervised, programmed K-means clustering algorithm to play out the division assignment of wheat leaf scab image in view of the Lab colour space. The investigations on wheat leaf images with three basic sicknesses demonstrated the acceptable execution of their technique as far as precision, productivity, and robotization. They find that the expanded precision in the division will help with taking after procedures, for automatic disease detection and investigation of a wheat leaf.

\subsection{Thresholding}

Threshold is another simplest method of segmentation. In this method the threshold value is calculated by converting image to binary image. Thresholding methods are of two types, global and local thresholding, which having methods like Otsu global thresholding and Adaptive local thresholding [20].

W. Abudullakasim et al. [14] introduced a procedure for measurement of severity degree of brown spot in cassava leaves. He introduced the Otsus' method for this purpose. He used image enhancement techniques for image analysis and for segmenting the image used the Otsus' method.

\subsection{Edge based segmentation}

Edge detection is a process of locating an edge of an image. Detection of edges in an image is a very important step towards understanding image features. 
Edges consist of meaningful features and contained significant information [20]. It reduces significantly the amount of the image size and filters out information that may be regarded as less relevant, preserving the important structural properties of an image. Since edges often occur at image locations representing object boundaries, edge detection is extensively used in image segmentation when images are divided into areas corresponding to different objects.

There are many methods of detecting edges; the majority of different methods may be grouped into these two categories:

Gradient: The gradient method detects the edges by looking for the maximum and minimum in the first derivative of the image. For example Roberts, Prewitt, Sobel operators detect vertical and horizontal edges. Sharp edges can be separated out by appropriate thresholding.

Laplacian: The Laplacian method searches for zero crossings in the second derivative of the image to find edges.

Shen Pan et al. [22] introduced a fuzzy numerical morphology calculation to distinguish the edge. An effectiveness of edge recognition in light of the fuzzy mathematic morphology was demonstrated by contrasting and the results of alternate calculations, for example, Sobel and binary morphology, the edge identification calculation proposed by this paper have pointed of interest like no threshold required, high invulnerability to noise, extraction of texture and the vein. Additionally, research is to figure the area of tobacco leaf and the length of a vein in light of the consequence of edge recognition.

\subsection{Region based segmentation}

The main idea here is to classify a particular image into a number of regions or classes. Thus for each pixel in the image we need to somehow decide or estimate which classes it belongs to. There are a variety of approaches to do region based segmentation and to our understanding the performance does not change from one method to the other considerably. Since the emphasis of this paper lies on an integrated boundary finding approach given the raw image and the region classified image, it does not matter too much which method is being used to get the region classified image as long as the output of that method gives reasonable results. The Main types of Region based Segmentation are Region Growing, Region Splitting and Region Merging [20].

Darshana A. et al. [18] introduced the region based segmentation techniques to find out the disease region. Out of the three basic techniques in region based segmentation they derived the methodologies that were used to select the best one. On the basics of the time analysis and quality metrics they found that Region growing gave the maximum peaks representing distinct regions having least discrete entropy and highest grey level energy as compared to the mean-shift segmentation methods.

\subsection{Watershed based segmentation}

Watershed segmentation is another region-based method that has its origins in mathematical morphology. In watershed segmentation an image is regarded as a topographic landscape with ridges and valleys. The elevation values of the landscape are typically defined by the gray values of the respective pixels or their gradient magnitude. Based on such a 3D representation the watershed transform decomposes an image into catchment basins. For each local minimum, a catchment basin comprises all points whose path of steepest descent terminates at this minimum. Watersheds separate basins from each other. The watershed transform decomposes an image completely and thus assigns each pixel either to a region or a watershed. With noisy medical image data, a large number of small regions arise. This is known as the "over-segmentation" problem.

PR. Hill et al. [23] presented the idea of texture gradient and have utilized it to create a successful watershed segmentation strategy for common images in light of intensity and texture boundaries. Moreover, a novel marker choice calculation has been executed to check the issue of over-division while holding key slope limits 
giving no little lingering districts. Utilizing this marker choice plan with a typical picture slope will regularly prompt powerful division for non-surface pictures. By using this markers removed from the created least district, moving edge and locale developing strategy, homogeneously finished areas can be distinguished. This marker extraction technique utilizes a similar inclination picture as the along these lines executed watershed change. All little scale inclination elements are consequently safeguarded regularly making a more powerful division.

\section{CLASSIFICATION TECHNIQUES BY SVM METHOD (SUPPORT VECTOR MACHINE)}

The SVM is a discriminative classifier that is used to separating hyper plane. In two dimensional spaces this hyper plane is a line dividing a plane in two parts where in each class lay in either side. It finds out a line in multi dimensional space that separates out classes. SVM technique also shows greater ability to generalize and greater likelihood of generating good classifiers.

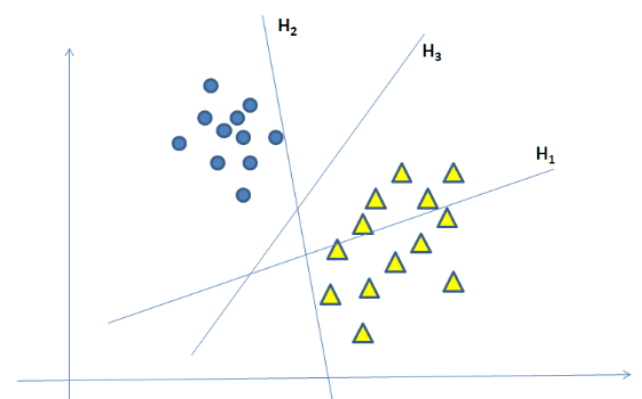

Fig. 2: Support Vector Machine diagram

\section{LITERATURE REVIEW}

In this section different types of methods are discussed which are used by different authors

Sachin D. Khirade et al. [1] focused on plant disease detection and classification. The authors used Kmeans clustering and Otsu's method to partitioning the disease part of the plant. They used feature extraction and classification techniques to extract the feature of infected leaves and the classification of plant diseases. Here the authors introduced ANN methods for classification of plant diseases.

Santanu Phadikaret et al. [2] used image processing techniques for identification of rice disease. They used image acquisition in their first step. After then they used segmentation, boundary detection and spot detection method for feature extraction of the infected parts of the leaves. The author introduced zooming algorithm in which classification of rice diseased image can be done by SOM (Self Organising Map) neural network.

Dheeb Al Bashishet et al. [3] present image processing techniques for detection of leaf and stem disease. Here the authors used image acquisition first. After then K-Means clustering method is used for segmentation. After segmenting for feature extraction CCM (Colour Co-occurrence Method) is used for texture analysis of infected leaf and stem. At last authors used back propagation algorithm for neural networks in classification of plant disease.

Zulkifli Bin Husin at al. [4] introduced both LABVIEW AND MATLAB to detect chili plant disease. In this method the image is captured using LABVIEW IMAQ vision and MATLAB is used for various operation of image processing. Here some preprocessing operations like Fourier filtering edge detection and morphological operations are used. The colour clustering is used to distinguish between chilli and non chilli leaves. Image classification and recognition are used to determine infected leaves of chili plant.

Ramakrishnan.Met et al. [5] used image processing techniques for groundnut plant disease detection. In this method after obtaining leaf images RGB are converted to HSV colour image. Feature extraction 
analysis, co-occurrence matrices techniques are used in colour and texture. There are two methods used for analyse the texture images. First one is structured approach and the second method is statistical approach. For classification and recognition of groundnut disease, back propagation algorithm is used. There are two phases in back propagation 1 . Propagation, 2. Weight update.

Ms. Monika Gupta et al. [6] used digital image processing techniques and MATLAB software for detection and classification of disease affected leaf. They implement K-means clustering and SVM algorithm to automatically detect of plant disease.

Sandesh Raut et al. [7] used K-means and multi SVM techniques which are used for both leaf and fruit disease detection

H.Al-Hiary et al. [8] used K-means clustering and neural networks for clustering and classification of disease. They tested this algorithm on five diseases named early scorch, cottony mold, ashen mold, late scorch a tinny whiteness.

Prakash M. Manikar et al. [9] used K-means clustering, GLCM and BPNN techniques to detect the tomato and potato leaf diseases. They used K-means clustering for plant disease segmentation and GLCM techniques are used for statistical value analysis.

Pallavi S. Maratheet et al. [10] used digital image processing and GSM for detecting the plant disease. They used Otsu's method, K-means clustering for image segmentation and convert the RGB to HSI model. SVM method is used to classification and detection of plant disease.

J. D. Pujari et al. [11] used the statistical procedure to detect the disease and then classify the fungal disease of fruits. Here the evolution of statistical features like block wise, GLCM and GLRM is done. The classification is done by using nearest neighbour with Euclidean distance.

R. G. Mundadaet et al. [12] used image processing techniques for detection and classification of pets in greenhouse. They used image acquisition in their first step and after then they performed some image preprocessing techniques like enhancement, RGB to gray conversion, resizing the image according to their needs. They used image filtering for cleaning up the image and after then SVM techniques is used for classification and detection.

S. Ananthiet et al. [13] introduced a method for fast detection and classification of plant diseases. According to that method first the image is taken by the digital camera and after then the image processing techniques are used and gather some important feature. The authors view three types of plant diseases that are viral fungal and bacterial. They used HSI and SGDM method to detect and classify the disease. HSI method is used to convert the RGB image and the SGDM method used for colour occurrence.

Gudinoet et al. [15] developed image processing techniques by java applet for determining and preventing the diseases in chilli peppers. It is less time consuming as compared to other methods like visual inspection, microscopic and biochemical methodologies. Authors used prewitt operator for better result.

P. Chaudhary et al. [16] introduced colour transformation approach to detect the disease on plant leaf. They used colour transformation, image smoothing and disease spot segmentation to detect the plant diseases. They used median filter to remove the noise. Selection of threshold of the gray level is required to extract the spotted disease from the leaves so for this purpose they used segmentation of spot diseases techniques. They used CIELAB techniques to 
detect the black, brown, white and gray coloured spots.

Youwen Tian et al. [17] introduced a technique in which expanse and grading time is reduced as compared to the manual system. Here the authors used three steps for the crop disease. First is the image pre-processing, second is segmentation of image and third one is statistical analysis. They used the median filter for filtering the image. The normal and infected areas are segmented by statistical pattern recognition.

\section{REVIEW TABLE}

This table gives all the information about the different methods which are used by different authors to detect the plant disease with their result.

TABLE- 1

REVIEW OF VARIOUS TECHNIQUES USED TO SEGMENTATION AND CLASSIFICATION OF LEAVES DISEASES

\begin{tabular}{|c|c|c|c|c|}
\hline SI no. & References & Topic & Methods used & Result \\
\hline 1 & $\begin{array}{l}\text { Sachin D. } \\
\text { Khirade et } \\
\text { al.[1] }\end{array}$ & $\begin{array}{l}\text { Plant Disease } \\
\text { Detection Using } \\
\text { Image Processing }\end{array}$ & $\begin{array}{l}\text { K-Means } \\
\text { clustering, } \\
\text { Otsu's method, } \\
\text { Multi SVM } \\
\text { classifier } \\
\text { ANN method }\end{array}$ & $\begin{array}{l}\text { Accurate detection and identification } \\
\text { of disease }\end{array}$ \\
\hline 2 & $\begin{array}{l}\text { Zulkifli Bin } \\
\text { Husin at } \\
\text { al.[4] }\end{array}$ & $\begin{array}{l}\text { Feasibility Study } \\
\text { On Plant Chilli } \\
\text { Disease Detection } \\
\text { Using Image } \\
\text { Processing } \\
\text { Techniques }\end{array}$ & $\begin{array}{l}\text { LABVIEW \& } \\
\text { MATLAB, } \\
\text { Colour clustering } \\
\text { method }\end{array}$ & $\begin{array}{l}\text { Reducing use of harmful chemicals } \\
\text { and reduces the production cost and } \\
\text { increase high quality of chilli }\end{array}$ \\
\hline 3 & $\begin{array}{l}\text { Ramakrishna } \\
\text { n.M et al.[5] }\end{array}$ & $\begin{array}{l}\text { Groundnut Leaf } \\
\text { Disease Detection } \\
\text { And Classification } \\
\text { By Using Back } \\
\text { Propagation } \\
\text { Algorithm }\end{array}$ & $\begin{array}{l}\text { HSV conversion, } \\
\text { Co-occurrence } \\
\text { matrices techniques } \\
\text { Back propagation } \\
\text { algorithm }\end{array}$ & $\begin{array}{l}\text { Classified four different diseases. } \\
\text { Those are cercospora, } \\
\text { cercosporidium personatum, alternia } \\
\text { leaf blight, phaeoisariopsis personata }\end{array}$ \\
\hline 4 & $\begin{array}{l}\text { Pallavi S. } \\
\text { Marathe et } \\
\text { al.[10] }\end{array}$ & $\begin{array}{l}\text { Plant Disease } \\
\text { Detection Using } \\
\text { Digital Image } \\
\text { Processing And } \\
\text { GSM }\end{array}$ & $\begin{array}{l}\text { Otsu's method, K- } \\
\text { means clustering, } \\
\text { SVM algorithm }\end{array}$ & $\begin{array}{l}\text { Due to GSM the message can be } \\
\text { transmission from one device to } \\
\text { another device after detecting the } \\
\text { disease }\end{array}$ \\
\hline
\end{tabular}




\begin{tabular}{|c|c|c|c|c|}
\hline 5 & $\begin{array}{l}\text { J. D.Pujari et } \\
\text { al.[11] }\end{array}$ & $\begin{array}{l}\text { Statistical Methods } \\
\text { for Quantitatively } \\
\text { Detecting Fungal } \\
\text { Disease from Fruits }\end{array}$ & $\begin{array}{l}\text { Nearest neighbor } \\
\text { classifier }\end{array}$ & $\begin{array}{l}\text { It can be implement on fungal } \\
\text { diseases and only for fruits. }\end{array}$ \\
\hline 6 & $\begin{array}{l}\text { R. G. } \\
\text { Mundada et } \\
\text { al.[12] }\end{array}$ & $\begin{array}{l}\text { Detection And } \\
\text { Classification Of } \\
\text { Pets In Green } \\
\text { House Using Image } \\
\text { Processing }\end{array}$ & $\begin{array}{l}\text { SVM and median } \\
\text { filter }\end{array}$ & $\begin{array}{l}\text { The flaws in static images and sticky } \\
\text { traps are covered. The median } \\
\text { operation is applied to all the pixel. }\end{array}$ \\
\hline 7 & $\begin{array}{l}\text { S. Ananthi et } \\
\text { al.[13] }\end{array}$ & $\begin{array}{l}\text { Detection and } \\
\text { Classification of } \\
\text { Plant Leaf Diseases }\end{array}$ & $\begin{array}{l}\text { HSI method and } \\
\text { SGDM method }\end{array}$ & $\begin{array}{l}\text { HSI is suitable for human perception } \\
\text { model but it is not supported standard } \\
\text { like JPEG }\end{array}$ \\
\hline 8 & $\begin{array}{l}\text { W. } \\
\text { Abudullakasi } \\
\text { m et al.[14] }\end{array}$ & $\begin{array}{l}\text { Assessment of the } \\
\text { Severity of Brown } \\
\text { Leaf Spot Disease } \\
\text { in Cassava using } \\
\text { Image Analysis }\end{array}$ & Otsu's method & $\begin{array}{l}\text { Reduces all the limitations like error } \\
\text { but time consuming }\end{array}$ \\
\hline 9 & $\begin{array}{l}\text { Gudino et } \\
\text { al.[15] }\end{array}$ & $\begin{array}{l}\text { Color Image } \\
\text { Segmentation } \\
\text { Using Perceptual } \\
\text { Spaces Through } \\
\text { Applets For } \\
\text { Determining And } \\
\text { Preventing } \\
\text { Diseases In Chili } \\
\text { Peppers }\end{array}$ & Perwitt filter & $\begin{array}{l}\text { The drawbacks like expensive } \\
\text { equipments, naked eye observation } \\
\text { are overcome by this method. HSL } \\
\text { and HSV could not find the diseased } \\
\text { area but identified the counter of the } \\
\text { leaves. }\end{array}$ \\
\hline 10 & $\begin{array}{l}\text { P. Chaudhary } \\
\text { et al.[16] }\end{array}$ & $\begin{array}{l}\text { Color Transform } \\
\text { Based Approach } \\
\text { for Disease Spot } \\
\text { Detection on Plant } \\
\text { Leaf }\end{array}$ & $\begin{array}{l}\text { Colour } \\
\text { transformation } \\
\text { techniques, } \\
\text { CIELAB } \\
\text { techniques }\end{array}$ & $\begin{array}{l}\text { Disease spots could not identified } \\
\text { accurately by applying threshold on } \\
\text { RGB image. Results was depending } \\
\text { on background type }\end{array}$ \\
\hline 11 & $\begin{array}{l}\text { Youwen } \\
\text { Tian et } \\
\text { al.[17] }\end{array}$ & $\begin{array}{l}\text { Grading Method Of } \\
\text { Crop Disease } \\
\text { Based On Image } \\
\text { Processing }\end{array}$ & $\begin{array}{l}\text { Median filter, } \\
\text { Statistical pattern } \\
\text { recognition }\end{array}$ & $\begin{array}{l}\text { Due to the vector median filter the } \\
\text { edges were detected very well. The } \\
\text { median operation is applied to each } \\
\text { pixel without taking care that this is } \\
\text { damaged or not in median filter. }\end{array}$ \\
\hline 12 & $\begin{array}{l}\text { Darshana A. } \\
\text { et al.[18] }\end{array}$ & $\begin{array}{l}\text { Segmentation } \\
\text { Method For } \\
\text { Automatic Leaf } \\
\text { Disease Detection }\end{array}$ & $\begin{array}{l}\text { Region based } \\
\text { segmentation }\end{array}$ & $\begin{array}{l}\text { On the basics of the time analysis } \\
\text { and quality metrics they found that } \\
\text { Region growing gave the maximum } \\
\text { peaks representing distinct } \\
\text { regions having least discrete entropy } \\
\text { and highest grey level energy as }\end{array}$ \\
\hline
\end{tabular}




\begin{tabular}{|l|l|l|l|l|}
\hline & & & & $\begin{array}{l}\text { compared to the mean-shift } \\
\text { segmentation methods. }\end{array}$ \\
\hline 13 & $\begin{array}{l}\text { E. Kiani et } \\
\text { al.[21] }\end{array}$ & $\begin{array}{l}\text { Identification Of } \\
\text { Plant Disease } \\
\text { Infection Using } \\
\text { Soft Computing: } \\
\text { Application To } \\
\text { Modern Botany }\end{array}$ & CPDA and FLCA & $\begin{array}{l}\text { Does not require the time consuming } \\
\text { training and neural network but gives } \\
\text { 97\% accuracy. }\end{array}$ \\
\hline
\end{tabular}

\section{CONCLUSION}

Detecting the plant disease accurately is the major topic in the field of agriculture. This review paper gives a survey of plant disease detection and classification by using image processing techniques. Different authors proposed different algorithm to detect the disease. The computational time is also saved by different algorithm. Authors used multi SVM classifier, K-means clustering, Otsu's method to give the high accuracy. These methods also save the computational time. From the methods the diseases are accurately detected and identify by less time consuming.

\section{REFERENCES}

[1]. Sachin D. Khirade and A.B. Patil "Plant Disease Detection Using Image Processing” 2015 International Conference On Computing Communication Control And Automation, IEEE, pp. 978-1-4799-6892.

[2]. Santanu Phadikar And Jaya Sil "Rice Disease Identification Using Pattern Recognition Techniques" 11th International Conference On Computer And Information Technology(ICCIT 2008), IEEE, PP. 1-4244-2136-7/08.

[3]. Dheeb Al Bashish, Malik Barik And Sulieman Bani Ahmad "A Frame Work For Detection And Classification Of Plant Leaf And Stem Diseases"
2010 International Conference On Signal And Image Processing, IEEE, pp. 978-1-4244-8594-9/10.

[4]. Zulkifli Bin Husin, Abdul Hallis Bin Abdul Aziz, Ali Yeon Bin Md Shakaff And Rohani Biniti S Mohamed Farook "Feasibility Study On Plant Chili Disease Detection Using Image Processing Techniques" 2012 3rd International Conference On Intelligent Systems Modelling And Simulation, IEEE, pp. 978-0-7695-4668-1/12.

[5]. Ramakrishnan.M And Sahaya Anselin Nisha.A "Groundnut Leaf Disease Detection And Classification By Using Back Propagation Algorithm" IEEE ICCSP 2015, conference, pp. 9781-4 799-8081-9/15.

[6]. Ms. Monika Gupta, Pabbathi Sravani, Reine D Bharali, S. Monica, Nanda Gopal Naik "Plant Disease Detection Using Digital Image Processing” International Journal Of Innovations \& Advancement In Computer Science (IJIACS), ISSN 2347-8616, volume 7, Issue 5, May 2018.

[7]. Sandesh Raut and Amit Fulsunge "Plant Disease Detection In Image Processing Using Matlab" International Joural Of Innovative Research In Science, Engineering And Technology (IJIRSET), volume 6, issue 6, june2017.

[8]. H.Al-Hiary, S. Bani-Ahmad, M.Reyalat, M.Braik \& Z.AlRahamneh, "Fast and Accurate Detection and Classification of Plant Diseases", International Journal of Computer Applications, Vol. 17, No.1, pp. 31-38.March 2011.

[9]. Prakash M. Manikar, Shreekant Ghorpade and Mayur Adawadkar "Plant Leaf Disease Detection and Classification Using Image Processing Techniques" International Journal of Innovative and 
Emerging Research in Engineering (IJIERE), volume 2, issue 4, 2015, e-ISSN :2394-3343, p-ISSN: 23945494.

[10]. Pallavi S. Marathe, G.H. Raisoni, Savitri Phule, "Plant Disease Detection Using Digital Image Processing And GSM", IJESC, volume 7, issue 4, April 2017.

[11]. J. D.Pujari, R. Yakkundimath \& A.S.Byadgi, "Statistical Methods for Quantitatively Detecting Fungal Disease from Fruits" Images", International Journal of Intelligent Systems \& Applications in Engineering Advanced Technology \& Science (IJISAE), volume 1 no.4, pp. 60-67, ISSN:2147-6799, 12th Dec2013.

[12]. R. G. Mundada, Dr. V.V. Gohokar, "Detection And Classification Of Pets In Green House Using Image Processing" IOSR Journal Of Electronics And Communication Engineering (ISOR-JECE) volume 5, issue 6, pp. 57-63, 2013.

[13]. S. Ananthi \& S.V. Varthini, "Detection and Classification of Plant Leaf Diseases", International Journal of Research in Engineering \& Applied Sciences, Volume 2, Issue 2, pp.763-773, February 2012.

[14]. W. Abudullakasim \& J. Unartngam, "Assessment of the Severity of Brown Leaf Spot Disease in Cassava using Image Analysis", The International conference of the Thai Society of Agricultural Engineering, 2012.

[15]. Gudino, J. Gudino-Bazaldua, J. L. Rojas-Renterai, V. Rodrgiuez-Hernandez and V.M. Castano, "Color Image Segmentation Using Perceptual Spaces Through Applets For Determining And Preventing Diseases In Chili Peppers", African Journal of Biotechnology Volume 12, no.7, pp. 679688, 2013.

[16]. P. Chaudhary, A. K. Chaudhari, Dr. A. N. Cheeran \& S. Godara, "Color Transform Based Approach for Disease Spot Detection on Plant Leaf', International Journal of Computer Science and Telecommunications, Volume 3, Issue 6, June 2012.

[17]. Youwen Tian, Lide Wang and Qiuying Zhou, "Grading Method Of Crop Disease Based On Image Processing”, CCTA 2011, part II, IFIP AICT 369, pp. 427-433, 2012.
[18]. Darshana A., Jharna Majumdar, Shilpa Ankalaki, "Segmentation Method For Automatic Leaf Disease Detection”, IJIRCCE, Vol. 3, Issue 7, pp.1-7,2015.

[19]. Sandesh Raut And Kartik Ingole, "Review On Leaf Disease Detection Using Image Processing Techniques", International Research Journal Of Engineering And Technology (IRJET), volume 04, issue 04,apr-2017,e-issn: 2395-0056,p-issn:23950072.

[20]. S.S. Lomte, A.P. Janwale, "Plants Leaves Image Segmentation Techniques: A Review”, International Journal Of Computer Science And Engineering (IJCSE), Vol. 5, issue 5, E-ISSN:2347-2693

[21] Ehsan kiani, Tofik Mamedov, "Identification Of Plant Disease Infection Using Soft Computing: Application To Modern Botany", 9th international conference on theory and application of soft computing, computing with words and perception, ICSCCW 2017,24-25 august 2017, Budapest, Hungary.

[22] Shen Pan, "Edge Detection of Tobacco Leaf Images Based on Fuzzy Mathematical Morphology", The 1st International Conference on Information Science and Engineering (ICISE2009), Nanjing, pp. 12191222, 2009.

[23] PR. Hill, CN. Canagarajah, DR. Bull, "Image Segmentation Using a Texture Gradient Based Watershed Transform", IEEE Transactions on Image Processing, Vol. 12, No. 12, pp.16181633, 2003.

[24] Xiaojing Niu, "Image Segmentation Algorithm for Disease Detection of Wheat Leaves", 2014 IEEE Proceedings of the 2014 International Conference on Advanced Mechatronic Systems, Japan, pp.270-273, 2014

\section{Cite this article as :}

Soumya Ranjan Sahu, Chandra Sekhar Panda, "A Review On Leaves Disease Segmentation And Classification Techniques", International Journal of Scientific Research in Science and Technology (IJSRST), Online ISSN : 2395602X, Print ISSN : 2395-6011, Volume 6 Issue 3, pp. 132140, May-June 2019. Available at doi : https://doi.org/10.32628/IJSRST1196333 Journal URL :http://ijsrst.com/IJSRST1196333 